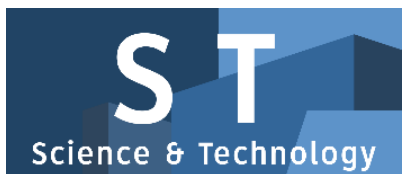

PAPER - OPEN ACCESS

\title{
Palm Juice/ Nira (Arenga pinnata (Wurmb) Merr.), A Source of Lactic Acid Bacteria from North Sumatera
}

\author{
Author : It Jamilah \\ DOI $\quad: 10.32734 /$ st.v1i2.291 \\ Electronic ISSN $\quad:$ 2654-7082 \\ Print ISSN $\quad$ : 2654-7074
}

Volume 1 Issue 2 - 2018 TALENTA Conference Series: Science \& Technology (ST)

\section{(ㅇ) $(1 \odot$}

This work is licensed under a Creative Commons Attribution-NoDerivatives 4.0 International License.

Published under licence by TALENTA Publisher, Universitas Sumatera Utara
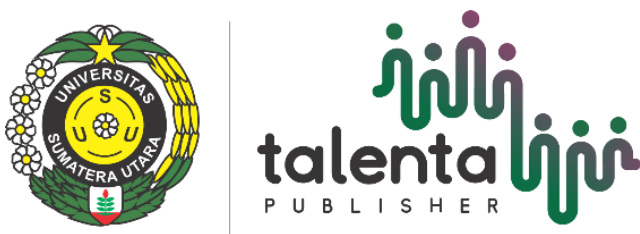


\title{
Palm Juice/ Nira (Arenga pinnata (Wurmb) Merr.), A Source of Lactic Acid Bacteria from North Sumatera
}

\author{
It Jamilah $^{\text {a* }}$, Nunuk Priyani ${ }^{\mathrm{a}}$ and Maretta Fitriani Silaban ${ }^{\mathrm{a}}$ \\ Department of Biology, Faculty of Mathematics and Natural Sciences, Universitas Sumatera Utara, Medan 20155, Indonesia \\ it_jamilah@yahoo.com; it@usu.ac.id
}

\begin{abstract}
Abstrak
Palm juice or being called Nira in North Sumatera, is a liquid produced from the base of the male flower cluster from Palm or Aren (Arenga pinnata L.). Nira contain sugar and other nutritional components that are suitable for the growth of microorganisms, one of which lactic acid bacteria (LAB). The purpose of this study was to isolate LABs that could inhibit growth of food pathogenic bacteria and to evaluate their potencies as probiotic candidates. Evaluation on probiotic properties were obtained from: Antagonisms assay against representative food pathogens (Salmonella typhimurium, Staphylococcus aureus and Escherichia coli), Survivability within simulated gastrointestinal tract (Gastric $\mathrm{pH}$ (2.0), Intestinal $\mathrm{pH}$ (7.2), Bile salts (0.5\% oxgall), and ability to form biofilm on the surface of solid stainless steel. Sixteen LABs were isolated and only six isolates have showed antagonisms against food pathogens. Five LABs namely MF5, MF10, MF11, MF14 and MF15 were able to survive in simulated condition of gastrointestinal tract and to form biofilm on the surface of solid stainless steel. The results showed prospective aspects of LABs as local probiotic candidates.
\end{abstract}

\section{Introduction}

Lactic Acid Bacteria (LAB) is a group of Gram-positive bacteria, non spore-former with rod and coccus cell shapes. These microorganisms are commonly used as probiotics which may exert health promotion when included into human diets. LABs can be found in diverse habitat such as: Animal faece or intestine tract, Human, Vegetables and its fermentation product, Fermented beverage or material, Pickle or kimchi, Sourdough, Dairy products, Fermentation meat-based material or food, Silage or animal food, Environment and Compost [1]. For safety issue, the main concern in isolating LABs have been focused on animal or human origins and fermented products.

Indonesia, with diversity in cultural processing of raw and fermentation products that have been handed down through generations, have contributed in discovery of LABs and its prospective use as probiotics through scientific studies. Research on health-promoting LAB have been conducted separately by many authors, mainly by isolating the LABs and evaluating its probiotic properties in vitro and by conducting few clinical studies [2]. However, the researches are mainly based on isolated LABs from fermented food and dairy products while information on indigenous LABs from beverage or fruit material are still limited in Indonesia.

Sugar palm (Arenga pinnata) is the most important sugar palm of the humid tropics including Indonesia. The palm juice in which liquid be obtained by tapping only from male inflorescence stalks have provided valuable source of high sugar components for human consumption [3]. The high sugar components of its liquid indicate a possibility of contamination by microorganisms, one of which are Lactic Acid Bacteria from the environment. Other studies have 
showed an indication to presence of LABs population in other palm such as Elaeis guineensis and Borassus akeassii $[4,5]$.

Sugar Palm or Aren (Arenga pinnata) grow well in Indonesia, especially in North Sumatera, and are heavily utilized for its palm juice or Nira. Local ethnic from North Sumatera, Bataknese people have long consumed Nira as fermented beverage called Tuak and as main ingredient to produce brown sugar or Gula Merah. As LABs can be isolated from high sugar environment, the study will reveal Nira as potential source of LABs as probiotic candidates following particular properties. In addition, we are hoped to add some informations regarding Nira consumption for health issue.

\section{MATERIALS AND METHODS}

\subsection{Population of Lactic Acid Bacteria during Nira Fermentation}

Fresh palm juice or Nira were sampled from random Aren (Arenga pinnata) trees grown at Pangaribuan, Regency of North Tapanuli, North Sumatera. Samples were stored in cool temperature prior laboratory experiments. Nira were kept to spontaneous fermentation for $48 \mathrm{hr}$. Paremeters like indigenous LAB population, temperature and $\mathrm{pH}$ were measured at interval of $12 \mathrm{hr}$ during fermentation time. An aliquot of one mililitre was serially diluted (102-105) prior plating into de Man, Rogosa, Sharpe agar (MRSA, Oxoid ${ }^{\mathrm{TM}}$, UK) supplemented with $\mathrm{CaCo} 3$ (Merck®, Germany) to obtain population of LAB in terms of log Colony Forming Unit (CFU) per mL.Temperature and pH were measured using standard analytical instrument.

\subsection{Lactic Acid Bacteria Isolation and Characterization}

Lactic Acid Bacteria (LAB) were isolated from fresh sample by serial dilution plating (102-105) into selective LAB agar medium, de Man, Rogosa, Sharpe agar (MRSA, Oxoid ${ }^{\mathrm{TM}}$, UK) supplemented with CaCo3 (Merck ${ }^{\circledR}$, Germany). Mesophilic LAB Strains were characterized morphologically by examining halo zone around colonies and differentiated by results of standard biochemical test, negative (-) catalase activity, gas production, fermentation type and gram staining.

\subsection{Antagonism Assay}

Isolated LABs and representative food pathogenic bacteria were grown overnight on Nutrient Broth (Merck®, Germany) to achieve $108 \mathrm{CFU} \mathrm{mL}-1$ or adjusted to $0,5 \mathrm{McFarland}$ standard. Food pathogens (Salmonella typhimurium, Staphylococcus aureus and Escherichia coli) were acquired from Laboratory of Microbiology, Faculty of Medicine, University of Sumatera Utara. Pathogens were swabbed aseptically into Mueller Hinton Agar (Merck®, Germany) and sterile paper disc (Oxoid ${ }^{\mathrm{TM}}$, UK) impregnated with $10 \mu \mathrm{L}$ of LABs were placed on top of agar. Antagonism were evaluated after overnight incubation by measuring inhibition zone around paper discs. Selected LABs were then assessed for their potentials as probiotic candidates in further experiments.

\subsection{Acid Tolerance Assay}

Simulated gastro-intestinal (GI) experiment was modified from [6] regarding the use of two pH-adjusted medium. Lactic Acid Bacteria were grown overnight in MRS broth. MRS broths with $\mathrm{pH} 2$ and 7,2 representing condition of simulated GI were adjusted using $\mathrm{HCl}$ and $\mathrm{NaOH} 0,1 \mathrm{~N}$. One mililitre of overnight LAB culture (108 CFU mL-1) was inoculated into adjusted MRS broths and incubated for $90 \mathrm{~min}$ in mesophilic condition. After incubation, one mililitre of culture was serially diluted and pour plated into MRSA. The plates were incubated for $24 \mathrm{hr}$. Viability of LAB colonies were counted before and after exposure to simulated GI and expressed in percentage (\%). 


\subsection{Bile Salt Tolerance Assay}

Bile salt tolerance assay was modified from [6] regarding composition of oxgall into medium. Lactic Acid Bacteria were grown overnight in MRS broth. MRS broths supplemented with 0,5\% oxgall (Merck®, Germany) with $\mathrm{pH} 7,2$ were used in this assay. One mililitre of overnight LAB culture (108 CFU mL-1) was inoculated into MRS broths and incubated for $240 \mathrm{~min}$ in mesophilic condition. After incubation, one mililitre of culture was serially diluted and pour plated into MRSA. The plates were incubated for $24 \mathrm{hr}$. Viability of LAB colonies were counted before and after exposure to bile salt and expressed in percentage (\%).

\subsection{Attachment Assay of Selected LABs on Stainless Steel}

Selected LABs were evaluated for its ability to form biofilm on stainless steel chips. The experiment was modified from [7] regarding the technical procedure and dimension of chips. Sterilized stainless steel chips measuring $1 \mathrm{~cm} 2$ were immersed into flasks containing MRS broth (108 CFU mL-1 inoculum load of LABs). Flasks were shaken for three days in $100 \mathrm{rpm}$. After incubation, chips were taken out aseptically and inserted into tubes containing sterile physiological saline and 0,5 g microglass beads. Suspension were vortexed for $2 \mathrm{~min}$ and aliquot was serially diluted until 10-5. One mililitre of diluted suspension was then plated into MRSA under mesophilic condition. Biofilm cells of detached LABs from chips were counted and expressed in CFU mL-1.

\section{Results}

The reaction or mathematical equation should be positioned symmetrically on the column, marked by sequential numbers written on the right corner within brackets. If the writing of equation takes more than one line, numbers should be written on the last line. Letters used as mathematical symbols in the text should be written in italics such as $\mathrm{x}$. Equations in the text should be referred to as abbreviations, for example equation (1). Make sure the equation is made with equation function (in M.S. Word) or using LaTex equation form (definitely we do not accept equation put as a picture).

Preliminary experiment on Nira fermentation in laboratory condition were performed to obtain trendline of LAB population within $48 \mathrm{hr}$. Temperatures were slightly different between intervals $\left(29-30,3^{\circ} \mathrm{C}\right.$, data not shown) while $\mathrm{pH}$ declined drastically during $12 \mathrm{hr}$ and steady until the end of fermentation. The highest LAB population was detected at $24 \mathrm{hr}$ as presented in Figure 1.

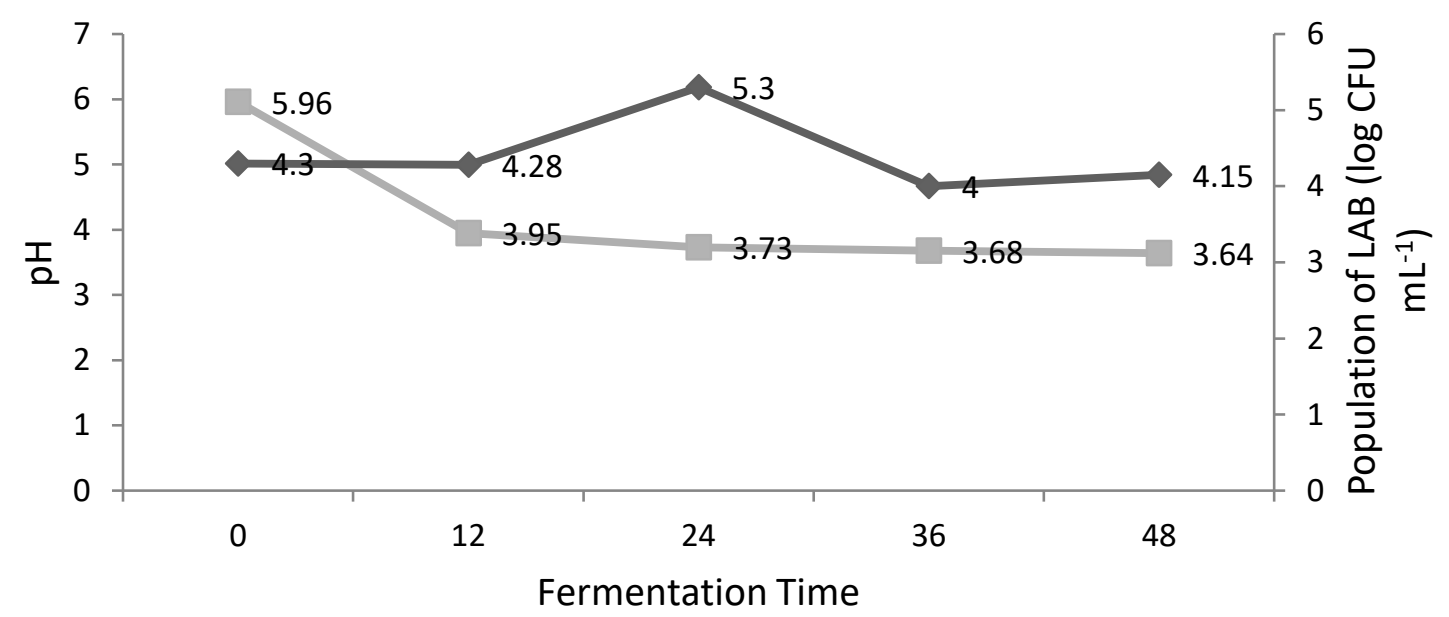


Figure 1. Population of LAB during Nira fermentation in laboratory. Black lines represented colony counts in log CFU $\mathrm{mL}^{-1}$; Grey lines represented $\mathrm{pH}$ changes during fermentation

Isolation of LABs from Nira using selective medium MRSA, found sixteen isolates that were differentiated by biochemical and morphological characters as presented in Table 1. All isolates were found to be gram positive, negative catalase activity, and non-motile. Ten out of sixteen isolates showed heterofermentative properties which indicated production of product besides lactic acid. Most isolated LAB showed antagonisms against food pathogens with varied inhibition zones. The most potential antagonistic LAB were isolates MF5, MF10, MF11, MF13, MF14 and MF15 among others with result of inhibition zone $\geq 8 \mathrm{~mm}$. Isolate MF13 showed the highest inhibition among potential isolates. Results of antagonism assay are presented in Table 2.

Table 1. Morphological Characters of Isolated LABs

\begin{tabular}{|c|c|c|c|}
\hline Code & Colony Morphology & Cell Shape & Fermentation Type \\
\hline MF1 & Circular, Entire, Convex, White & Cocci & Hetero fermentative \\
\hline MF2 & Irregular, Entire, Convex, Cream & Cocci & Homo fermentative \\
\hline MF3 & Irregular, Entire, Convex, White & Cocci & Heterofermentative \\
\hline MF4 & Circular, Entire, Convex, White & Coccobacilli & Hetero fermentative \\
\hline MF5 & Circular, Entire, Convex, Yellow & Cocci & Hetero fermentative \\
\hline MF6 & Irregular, Entire, Convex, Yellowish White & Cocci & Homofermentative \\
\hline MF7 & Irregular, Entire, Convex, White & Cocci & Hetero fermentative \\
\hline MF8 & Irregular, Entire, Convex, Yellow & Cocci & Homo fermentative \\
\hline MF9 & Circular, Entire, Convex, Yellowish White & Cocci & Heterofermentative \\
\hline MF10 & Circular, Entire, Convex, Cream & Cocci & Heterofermentative \\
\hline MF11 & Circular, Entire, Convex, Yellowish White & Cocci & Homofermentative \\
\hline
\end{tabular}




\begin{tabular}{|c|c|c|c|}
\hline MF12 & Irregular, Entire, Convex, White & Cocci & Heterofermenattive \\
\hline MF13 & Circular, Entire, Convex, Yellowish White & Cocci & Homofermentative \\
\hline MF14 & Circular, Entire, Convex, Yellow & Rod & Heterofermentative \\
\hline MF15 & Circular, Entire, Convex, Yellow & Heterofermentative \\
\hline MF16 & Circular, Entire, Convex, Cream & Cocci & HomoFermentative \\
\hline
\end{tabular}

Table 2. Antagonism Results against Food Pathogens

\begin{tabular}{|c|c|c|c|}
\hline \multirow{2}{*}{ Code } & \multicolumn{3}{|c|}{ Diameter of Inhibtion Zone (mm) } \\
\cline { 2 - 4 } & Salmonella typhimurium & Staphylococcus aureus & Escherichia coli \\
\hline MF1 & 6.5 & 8.25 & 8.62 \\
\hline MF2 & 0 & 0 & 0 \\
\hline MF3 & 0 & 0 & 7.37 \\
\hline MF4 & 0 & 7.25 & 8.87 \\
\hline MF5 & $\mathbf{9 . 7 5}$ & $\mathbf{9 . 1 2}$ & $\mathbf{8 . 0 0}$ \\
\hline MF6 & 9.25 & 8.25 & 0 \\
\hline MF7 & 0 & 8.37 & 10.12 \\
\hline MF8 & 8.75 & 7.75 & 6.50 \\
\hline MF9 & 8.87 & 7.12 & 6.75 \\
\hline MF10 & $\mathbf{8 . 5}$ & $\mathbf{8 . 2 5}$ & $\mathbf{8 . 7 5}$ \\
\hline MF11 & $\mathbf{9 . 6 2}$ & $\mathbf{8 . 1 2}$ & $\mathbf{9 . 6 2}$ \\
\hline MF12 & 8.75 & 8.12 & 6.25 \\
\hline MF13 & $\mathbf{1 1 . 7 5}$ & $\mathbf{1 1 . 6 2}$ & $\mathbf{8 . 8 7}$ \\
\hline MF14 & $\mathbf{9 . 7 5}$ & $\mathbf{1 0 . 2 5}$ & $\mathbf{9 . 2 5}$ \\
\hline MF15 & $\mathbf{1 1 . 6 2}$ & $\mathbf{8 . 3 7}$ & $\mathbf{8 . 7 5}$ \\
\hline MF16 & 6.87 & 11.00 & 9.00 \\
\hline
\end{tabular}

Six LABs with antagonistic properties were then subjected to evaluation as probiotic candidates. The tolerance of LABs within acidic and bile salt environment were evaluated under simulated Gastro-Intestinal tract experiments. All LABs showed viability of cells above $50 \%$ within acidic $(\mathrm{pH} 2)$, mild (pH 7,2) and bile salt environment as presented in Figure 2. Only one isolate, MF13 which was unable to withstand the bile salt environment. 
All LABs have showed ability to form biofilm on stainless steel chips within three days of incubation as presented in Figure 3. The use of microglass beads was meant to detached biofilm cells that formed on stainless steel chips. The

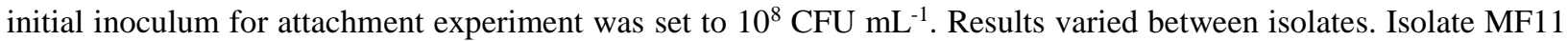
had the highest colony count reaching $\log 7 \mathrm{CFU} \mathrm{mL} \mathrm{mL}^{-1}$.

Isolate MF5 had the lowest colony count with colony count of only $\log 0,5 \mathrm{CFU} \mathrm{mL}^{-1}$.

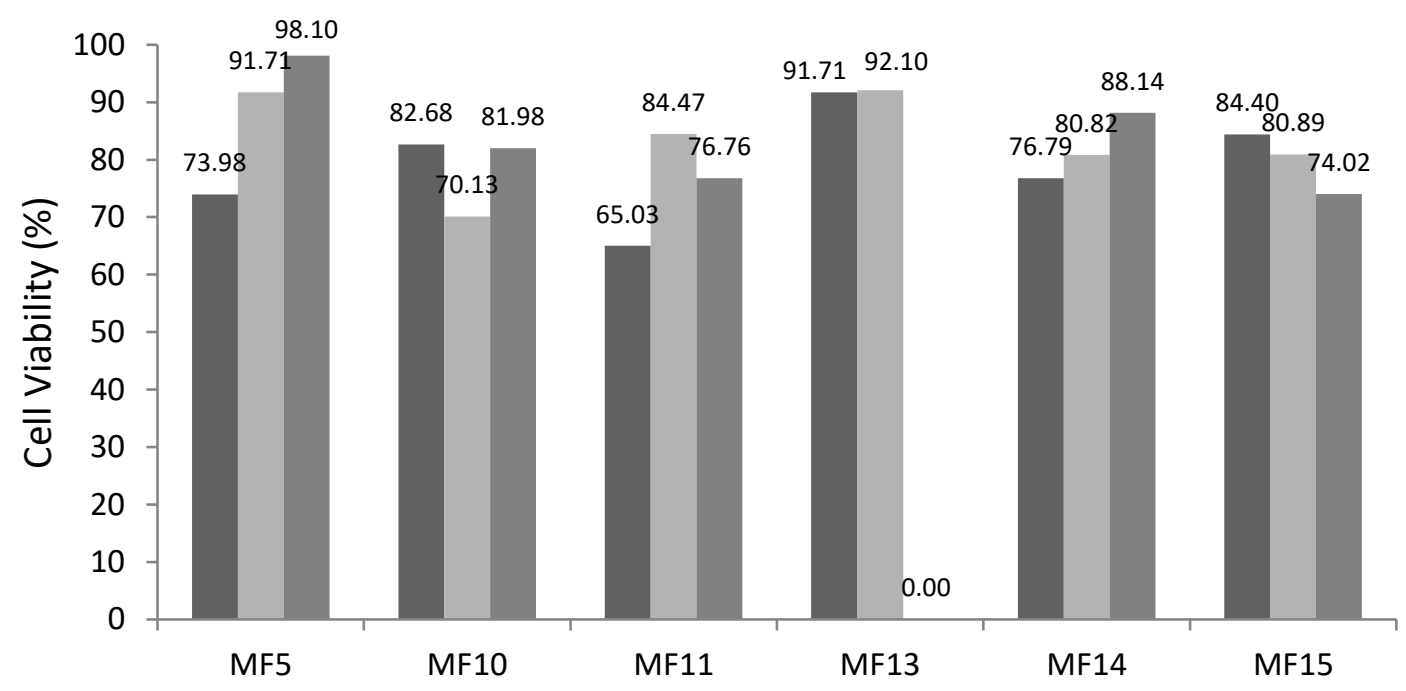

Figure 2. Survivability of LAB isolates during exposure to in vitro simulated gastric $(\square, \mathrm{pH}$ 2), intestinal (, pH 7,2) condition for 90 min and bile salt tolerance $(\square, 0,5 \%$ oxgall) for $240 \mathrm{~min}$

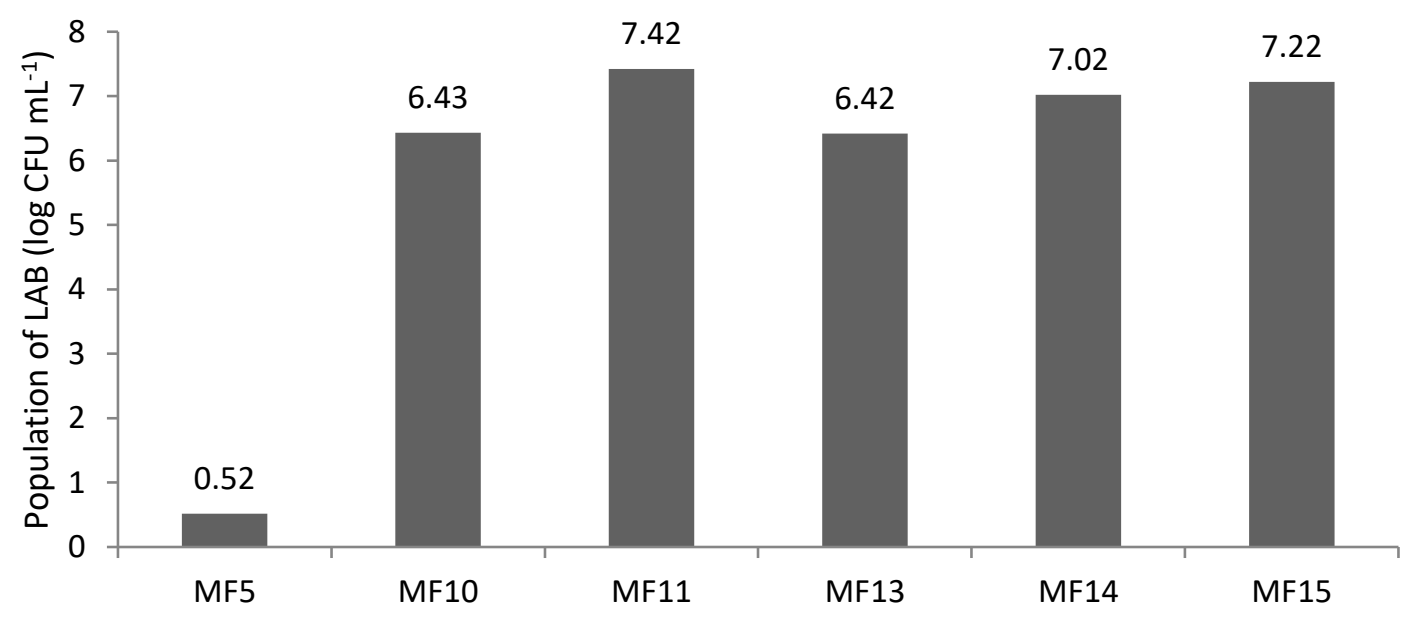

Figure 3. Population of detached LAB biofilm cells from stainless steel chips incubated for three days 


\section{Discussions}

All authors are required to complete the TALENTA Conference Series exclusive license transfer agreement before the article can be published, which they can do online. This transfer agreement enables TALENTA Conference Series to protect the copyrighted material for the authors, but does not relinquish the authors' proprietary rights. The copyright transfer covers the exclusive rights to reproduce and distribute the article, including reprints, photographic reproductions, microfilm or any other reproductions of similar nature and translations. Authors are responsible for obtaining from the copyright holder, the permission to reproduce any figures for which copyright exists.

From our study, Nira is considered to be a rich source of lactic acid bacteria. Information regarding successful isolation of lactic acid bacteria from Nira are still less reported. Other study only reported microbiological profile of pasteurized and filtered Nira for $15 \mathrm{hr}$ in laboratory experiment, inhabited dynamically by bacteria, mold and yeasts [8]. Moreover, research on LAB isolated from fruit and fermented material tend to focus on microbiological profile, by studying the population of indigenous yeasts, acetic acid bacteria and LABs [4, 5, 9].

Relatives to Arenga pinnata are also studied for its LAB population and acidity $\mathrm{pH}$. Titratable acidity or $\mathrm{pH}$ from B. akeassii ranged between 3,48-4,12, a much similar to A. pinnata in which $\mathrm{pH}$ at the end of fermentation reaching 3,64 [5]. Drop of acidity from E. guineensis are detected in $24 \mathrm{hr}$ fermentation with value of 4,5-4,0 while in our study, rapid decline in $\mathrm{pH}$ already occured in $12 \mathrm{hr}$ reaching 3,95; indicating fast accumulation and synthesis of acidic compounds by indigenous microbes [4].

Our results on total population of LABs during fermentation may be considered lower than other studies. Total population of culturable LABs from B. akeassii ranging between $\log 7$ to $8 \mathrm{CFU} \mathrm{mL}-1$ while from E. guineensis ranging between $\log 5$ to $9 \mathrm{CFU} \mathrm{mL}-1$. Our study found a steady trendline of colony count between $\log 4$ to $5 \mathrm{CFU}$ $\mathrm{mL}-1$. The result may be caused by other competing microbes, yeasts and acetic acid bacteria which are not yet to be revealed in this study.

The palm juice or sap from Bandji, Borassus akeassii is found to be colonized by thirty LAB isolates. Most of them are gram positive and negative (-) catalase rods with less cocci represented by only six isolates [5]. Similar result are also found in E. guineensis with dominant gram positive rods [4]. In contrary, our study found more cocci-shaped LABs than previous studies. Important cocci-shaped LAB species already being reported as important probiotics such as members of Aerococcaceae, Enterococcaceae, Leuconostocaceae and Streptococcaceae [1]. Further identification using molecular technique are needed to precise naming of our potential LAB isolates.

Probiotic candidates may be evaluated by performing certain scienfitic parameters. In our study, we conducted antagonism assay, tolerance assay within simulated GI tract and biofilm assay on metal surfaces using stainless steel chips. Regarding antagonism assay, probiotics are meant to inhibit the growth of pathogenic microbes. Methods for detecting antagonism may be varied among studies. Several methods have been employed such as: spot-on-lawn, double layer and agar well diffusion for bacteriocin compound [6,10,11]. Our study resulted in varied degree of inhibition among LAB isolates. We used disc diffusion method as indication of antagonism as this method is simple to perform. Six isolates namely MF5, MF10, MF11, MF13, MF14 and MF15 showed promising antagonistic activity against all food pathogens. Lactic acid bacteria have been known to produce arsenal of antimicrobial compounds such as organic acids, hydrogen peroxide and mainly bacteriocin when competing with other microbes. We did not report our results on cell-free supernatant tested against food pathogens since neutralized supernatant did not show any inhibition.

Gastrointestinal tract is target delivery of probiotics when administered into physiological body. The acid and bile salt tolerance assay are meant to select persistant LAB isolates to be applied in animal or human. Six selected LAB isolates showed different tolerance within acidic and bile salt environment. Initial inoculum load for each isolates were adjusted to $\log 10 \mathrm{CFU} \mathrm{mL}-1$. In this study, percentage of cell viability (\%) ranged from 65 to $92 \%$ in $\mathrm{pH}$ experiments while in bile salt experiment, ranged from 0 to $98 \%$. Only one isolate namely MF13 is sensitive to bile salt environment ( $0 \%$ viability) rendering cells to multiply and grow. Previous study has reported different tolerance of isolated LABs from commercial products with percentage of cell viability between 60 to $80 \%$ in pH and bile salt experiments [6]. Indigenous LABs isolated from traditional milk from Sumbawa gave similar results in tolerance compared to control strain, Lactobacillus rhamnosus GG ATCC53103 which are commonly used as commercial probiotics [12]. We 
assumed that evaluating wild type LABs strain from natural source in the future may provide us with more adaptable strains as probiotic candidates. Other future approach to overcome physiological stress to administered probiotics, is by using immobilization and encapsulation technology using various matrices and techniques.

Lactic acid bacteria are capable of forming biofilm on certain surfaces. In this study, six isolates were able to form biofilm on metal surface within three days of incubation. Isolates had different ability to form biofilm cells in terms of CFU mL-1. Three highest colony count was found from isolate MF11, MF15 and MF14 reaching $\log 7$ CFU mL1 , followed by MF 10 and MF13 with $\log 6$ CFU mL-1. The lowest colony count was from MF5 with only log 0,5 CFU mL-1. The results indicate the use of antagonistic LAB as biosanitizer into food material against food spoilage bacteria. Previous study reported the use of LAB cocktail by three LAB species (Lb. animalis, Lb. amylovorus, Pediococcus acidilactici) and found a succesful prevention of biofilm-forming Listeria monocytogenes, a food spoilage bacteria [13]. However, it should be noted that biofilm-forming LAB also caused notable cases like food spoilage and deterioration in food industry $[14,15]$. Concern for further study is to characterize spoiling properties of isolated LABs for safety issue in the future.

\section{Conclusion And Suggestion}

Nira is a rich source of indigenous lactic acid bacteria. Isolated LAB had potentials as probiotic candidates. Six among sixteen isolates showed considerable good results in antagonisms assay, simulated gastrointestinal assay and biofilm assay. Further investigation are needed to uncover other potential indigenous microbes from Nira e.g. yeasts and non-LAB to be evaluated as probiotic candidates. Other probiotics biological parameters are also needed to be studied for safety issue .

\section{Acknowledgement}

The authors would like to express gratitude to Bonggas Silaban for providing us shelter and access to the Sugar Palm (Arenga pinnata) forest at Pangaribuan, Regency of North Tapanuli during sampling. 


\section{Referensi}

[1] Liu W, H Pang, H Zhang and Y Cai. 2014. Biodiversity of Lactic Acid Bacteria. Book chapter: 2014. Lactic Acid Bacteria. Dordrecht. Springer Science+Business.

[2] Nuraida L. 2015. A review: Health promoting lactic acid bacteria in traditional Indonesian fermented foods. Food Science and Human Wellness 4:47-55.

[3] Mogea J, B Seibert and W Smits. 1991. Multipurpose palms: the sugar palm (Arenga pinnata (Wurmb.) Merr.). Agroforestry Systems13: 111129.

[4] Amoa-Awua WK, E Sampson and K Tano-Debrah. 2007. Growth of yeasts, lactic and acetic acid bacteria in palm wine during tapping and fermentation from felled oil palm (Elaeis guineensis) in Ghana. Journal of Applied Microbiology102: 599-606.

[5] Ouoba LII, C Kando, C Parkouda, H Sawadogo-Lingani, B Diawara and JP Sutherland. 2012. The microbiology of Bandji, palm wine of Borassus akeassii from Burkina Faso: identification and genotypic diversity of yeasts, lactic acid and acetic acid bacteria. Journal of Applied Microbiology113: 1428-1441.

[6] Lin WH, CF Hwang, LW Chen and HY Tsen. 2006. Viable counts, characteristic evaluation for commercial lactic acid bacteria products. Food Microbiology23: 74-81.

[7] Bastard A, C Coelho, R Briandet, A Canette, R Guogeon, H Alexandre, J Guzzo and S Weidmann. 2016. Effect of biofilm formation by Oenococcus oeni on Malolactic fermentation and the release of aromatic compounds in Wine. Frontiers in Microbiology7(613): 1-14.

[8] Mulyawanti I, N Setyawan, ANA Syah and Rishaferi. 2011. Evaluasi mutu kimia, fisika dan mikrobiologi Nira Aren (Arenga pinnata) selama penyimpanan. Agritech31(4): 325-332.

[9] Nyanga LK, MJR Nout, TH Gadaga, B Theelen, T Boekhout and MH Zwietering. 2007. Yeasts and lactic acid bacteria microbiota from masau (Ziziphus mauritiana) fruits and their fermented fruit pulp in Zimbabwe. International Journal of Food Microbiology120: 159-166.

[10] Perin LM and LA Nero. 2014. Antagonistic lactic acid bacteria isolated from goat milk and identification of a novel nisin variant Lactococcus lactis. BMC Microbiology14(36): 1-9.

[11] Desniar, I Rusmana, A Suwanto and NR Mubarik. 2013. Characterization of lactic acid bacteria isolated from an Indonesian fermented fish (bekasam) and their antimicrobial activity against pathogenic bacteria. Emirrates Journal of Food and Agriculture25(6): 489-494.

[12] Shi T, K Nishiyama, K Nakamata, NPD Aryantini, D Mikumo, Y Oda, Y Yamamoto, T Mukai, IN Sujaya, T Urashima and K Fukuda. Isolation of potential probiotic Lactobacillus rhamnosus strains from traditional fermented mare milk produced in Sumbawa Island of Indonesia. Biosci. Biotechnol. Biochem. 76(10): 1897-1903.

[13] Ndahetuye JB, OK Koo, CA O’Bryan, SC Ricke and PG Crandall. Role of lactic acid bacteria as a biosanitizer to prevent attachment of Listeria monocytogenes F6900 on deli slicer contact surfaces. Journal of Food Protection75(8): 1429-1436.

[14] Kubota H, S Senda, N Nomura, H Tokuda and H Uchiyama. 2008. Biofilm formation by lactic acid bacteria and resistance to environmental stress. Journal of Bioscience and Bioengineering106(4): 381-386.

[15] Kuda T, A Nakano, H Takahashi and B Kimura. 2016. Effect of the quantities of food residues on the dessication resistance of spoilage lactic acid bacteria adhered to a stainless steel surfaces. Food Control68: 40-44. 